\title{
The use of autologous platelet rich plasma gel in bulbar and penile buccal mucosa urethroplasty: Preliminary report of our first series
}

\author{
Marcello Scarcia, Francesco Paolo Maselli, Giuseppe Cardo, Giuseppe Mario Ludovico \\ Urology Department "F. Miulli", General Hospital Acquaviva delle Fonti, Bari, Italy.
}

\begin{abstract}
Summary Objective: The Buccal Mucosa (BM) UrethroPlasty (UP) is one of the preferred treatments for long or compli-cated urethral strictures. We propose the use of autologous Platelet Rich Plasma gel (aPRPg) in order to enhance to vascularization of BM graft and reduce the fibrous spongy. We report the outcome of our ten cases of bulbar and penile UP and the safety of this technique.

Materials and metods: Ten patients underwent to BM UP with use of aPRP gel. Median age was 46. Stricture etiology was idiopathic, failed hypospadias and flogistic. Average stricture length was $3.7 \mathrm{~cm}$. All patient were preoperatively evaluated with uroflowmetry, retrograde urethrography, cystoscopy and questionnaire. The harvesting of the aPRP was performed in blood bank from peripheral venous sample. Catheter was usually removed after 3 weeks and urethrography was performed after 6 weeks.

Results: All patients reported no problem on the donor site. At time of follow-up (median 20 month, 12-34) all patients refer no problem and a good uroflowmetry. No re-strictures at the anastomotic sites were demonstrated in any of the patients.

Conclusion: However in our experience the follow-up is limited and no definitive conclusion or comparison can be made with the original BM UP. The use of aPRP gel seems feasible and safe.

In our opinion it is important to continue investigating this procedure for its advantages in case of complex urethral strictures complicated by fibrous spongy, above all in penile urethral strictures post hypospadia repair.
\end{abstract}

KEY WORDS: Buccal mucosa graft; Bulbar urethroplasty; Penile urethroplasty; Autologous platelet rich plasma gel; Urethral strictures.

Submitted 18 October 2016; Accepted 26 November 2016

\section{INTRODUCTION}

Numerous surgical techniques have been described to repair bulbar urethral strictures according to stricture length, including end-to-end anastomosis, augmented roof strip anastomotic urethroplasty, onlay repair using flap, or graft and multistaged procedures (1). Strictures longer than $3 \mathrm{~cm}$ are generally managed using tissue (skin or buccal mucosa) transfer procedures accomplished in a variety of ways including dorsal or ventral onlay graft urethroplasty $(8,12)$. Finally, in patients with strictures longer than $6 \mathrm{~cm}$ involving both penile and bulbar urethra or associated with local adverse conditions, multistage urethroplasty or mesh graft urethroplasty is mandatory. Buccal mucosal (BM) onlay graft urethroplasty (UP) is one of the most widely used methods for the repair of the strictures in the bulbar urethra and provides excellent results $(8,12,16)$. Stricture recurrences can, however, occur despite using an adequate surgical technique and substitution material may deteriorate over time $(16,17)$. Stricture recurrences after bulbar substitution onlay urethroplasty show two different features, namely, extensive fibrous tissue involving the entire grafted area or a short fibrous ring stricture at the distal or proximal anastomotic sites where the apices of the graft are sutured to the apices of the urethral plate (20).

We suggest here the use of autologous Platelet Rich Plasma gel (aPRPg) in a new technique of BM UP to reduce the failures in the treatment of penile urethral strictures after hypospadias repair.

\section{Methods}

Between January 2013 and October 2014, ten patients with a mean age of 40 years (range, 30-63 years) underwent urethroplasty using buccal mucosal graft and aPRPg. Six patients had bulbar strictures and four patient had penile strictures. Stricture etiology was in 4 cases idiopathic, 2 failed hypospadias and 4 phlogistic. Five patients had undergone previous urethrotomy or failed bulbar urethroplasty, two patients had undergone hypospadias repair. The average stricture length was 3.7 $\mathrm{cm}$ (range, 3-5 $\mathrm{cm}$ ) (Table 1). Two patients with bulbar strictures were managed using a dorsal (Asopa's technique) and ventral (McAninch's technique) grafts augmentation, like Palminteri's technique. The BM grafts were applied over the albuginea of the corpora cavernosa using as support aPRPg (Figure 3) and ventrally with interposition of aPRPg between the graft and spongiosa. Four patient with bulbar strictures were managed with Asopa's technique and use aPRPg as previously described. Two patient with penile strictures after hypospadias repair were managed with two-stage urethroplasty (Bracka's technique), and two others with onestage urethroplasty (Asopa's technique) (Table 1). 
Figure 1.

Autologous platelet rich plasma gel in sterile Petri capsule.

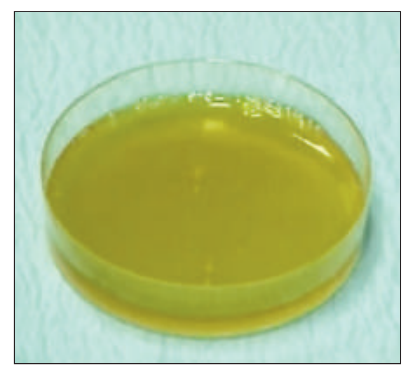

Figure 2.

Autologous platelet rich plasma gel shaped with a scalpel.
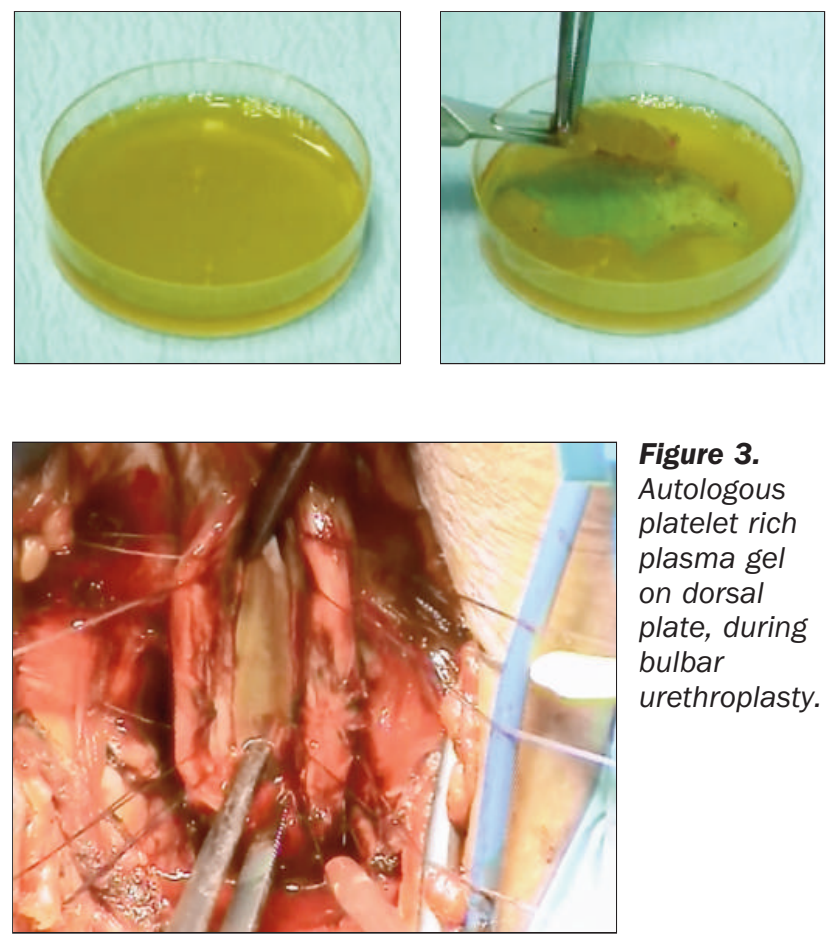

Figure 3.

Autologous platelet rich plasma gel on dorsal plate, during bulbar urethroplasty.

In penile urethroplasty the BM graft were applied using as support aPRPg.

\section{Preoperative evaluation}

Each patient's clinical history and chart were reviewed. Preoperative tests included urine culture, residual urine measurement, retrograde and voiding cystourethrography, urethroscopy and questionnaire (IIEF, IPSS).

The etiology of the stricture and its location and length (Table 1) were carefully examined to better define the characteristics needed in the buccal mucosal graft.

\section{Preparation of aPRPg}

In our institution, blood is drawn in the blood bank. To draw blood, a venous infusion catheter is placed in the patient's antecubital vein. Blood is collected in blood bags

\section{Table 1.}

Characteristic of urethral stricture and type of urethroplasty.

\begin{tabular}{|ll}
\hline Site and length of stricture & Type urethroplasty \\
\hline Bulbar $3 \mathrm{~cm}$ & Asopa \\
\hline Bulbar $3 \mathrm{~cm}$ & Asopa \\
\hline Bulbar $3 \mathrm{~cm}$ & Asopa \\
\hline Bulbar $3,5 \mathrm{~cm}$ & Asopa \\
\hline Bulbar $4 \mathrm{~cm}$ & Asopa - McAninch \\
\hline Bulbar $3,5 \mathrm{~cm}$ & Asopa - McAninch \\
\hline Penile $3 \mathrm{~cm}$ & One Stage Asopa \\
\hline Penile $4,5 \mathrm{~cm}$ & One Stage Asopa \\
\hline Penile $5 \mathrm{~cm}$ & Two Stage Bracka \\
\hline Penile $5 \mathrm{~cm}$ & Two Stage Bracka \\
\hline
\end{tabular}

(Campoflex Gel 8002125 Fresenius Emocare) containing an anticoagulant to prevent the blood from clotting. Predonation blood volumes (150 to $>500 \mathrm{~mL}$ of whole blood) can be obtained, resulting in a PRP volume ranging from 15 to $>50 \mathrm{~mL}$. Tabletop centrifuges have been used to manufacture smaller volumes of PRP from lesser amounts of whole blood (50-150 mL). The choice for system is mainly dependent on the type of surgical procedure, and thus the anticipated amount of PRP to be produced. For the picked decomposition unit, centrifugation at $1740 \mathrm{G}$ at $22^{\circ} \mathrm{C}$ for 6 minutes was used. At the end of centrifugation the aPRP werte distributed in 4 mini bags (each mini bag can contain $35 \mathrm{ml}$ of aPRP).

The aPRP product can be used in liquid form or activated with calcium gluconate to produce the aPRPg. The aPRP can be frozen at $-80^{\circ} \mathrm{C}$, and will be valid for six months. It will be thawed at the time of the clinical use. The thawing should take place at room temperature under sterile hood. To activate the aPRP the contents of the mini bags was aspirated and transferred to a sterile Petri capsule. Calcium gluconate was added as activator $(0.5 \mathrm{ml}$ for $5 \mathrm{ml}$ of aPRP). After mixing and waiting for about 15 minutes, aPRPg ready for clinical use was formed (Figure 1).

\section{Mechanisms of action}

Tissue repair and surgical wound healing are well orchestrated, and a complex series of events involving cell-cell and cell-matrix interactions in which platelet growth factors serve as messengers to regulate various regenerative processes.

Initially, tissue repair begins with activation of the coagulation cascade, platelet clot formation, platelet aggregation, and degranulation. During this degranulation period, the platelets release a pool of biologically active proteins (PDGFs) and other substances into the extracellular milieu. In this environment, the biologically active proteins might bind to specific platelet growth factor receptors present in surgical tissues. Released growth factors interact and bind with the platelet tyrosine kinase receptor (TKR), which is present in the cell membranes of tissue cells (ligand-receptor interaction) (21). Therefore, the actual binding site is on the outer surface of the cell membrane, and thus not directly on the cell nucleus. The TKR is a membrane spanning protein that extends into the cytoplasm of cells. After the platelet growth factor interacts with the external part of the TKR, activation of inactive messenger proteins occurs in the cytoplasm. Thereafter, the messenger proteins become activated and bind to the TKR cytoplasmic tail. Activated proteins are generated via an active signaling cascade in the cell nucleus where the genes responsible for control of cell division are triggered. Thus, transcription of messenger RNA is induced, producing a biological response that starts cascades, which in turn provoke tissue repair and tissue regeneration.

\section{Platelet growth factors in aPRP}

A variety of platelet growth factors are located in the alpha granules of platelets present in the PRP.

Platelet derived growth factor was one of the first growth factors to be identified in platelets. Subsequently, additional platelet growth factors have been identified, including transforming growth factor (TGF) and $ß$, fibroblast growth 
factor (FGF), insulin-like growth factor (IGF), epidermal growth factor (EGF), vascular endothelial growth factor (VGEF), and connective tissue growth factor (CTGF) (24). The platelet growth factors have their own specific function and biological activity. The concept of harvesting and concentrating autologous platelets with subsequent transfer and fixation to the wound site within the medium of an autologous soft tissue graft allows access to higher concentrations of multiple growth factors placed directly into the wound site (27).

\section{Infection prevention}

In addition to the Platelet Gel (PG) delivery of growth factors, limited data are available that deal with the role of leucocytes present in the Platelet Leucocytes Gel (PLG) to act as an antimicrobial component. It is also rich in concentrated leukocytes, in particular neutrophilic granulocytes, monocytes, and lymphocytes (29). Neutrophilic granulocytes and monocytes contain numerous granules full of myeloperoxidase, which catalyzes the oxidation of chloride to generate hypochlorous acid and other reactive oxygen derivates that act as potent bactericidal oxidants toxic to micro-organisms and fungi (31). Furthermore, Tang et al. (33) have maintained the idea that platelets are also involved in microbicidal activity, suggesting that platelets take part in the platelet host defense mechanism by releasing a variety of platelet microbicidal proteins.

\section{Wound healing}

During the initial days of wound healing, an inflammatory process is initiated by migration of neutrophils, and subsequently macrophages, to the wound site. In turn, activated macrophages release multiple growth factors, including platelet-derived growth factor, TGF, interleukin-1, and FGF (35). Angiogenesis and fibroplasia start shortly after day 3 , followed by collagen synthesis on days 3-5. This process leads to an early increase in woundbreaking strength, which is the most important woundhealing parameter of surgical wounds, followed by epithelialization and the ultimate remodeling process leading to a tissue scar (36). In PG the multiple platelet growth factors and other biological and adhesive proteins work together synergistically and promote mitogenesis of mesenchymal stem cells and growth factors at the surgical wound site, and therefore have the potential to accelerate and boost tissue healing (38).

\section{Sticking the graft using aPRPg}

The aPRPg arrived in the operating room in a sterile Petri dish (Figure 1), is shaped with a scalpel (Figure 2) according to the urethral plate to be rebuilt. Depending on the intervention to be performed is placed on the tunica albuginea of the corpora cavernosa and then overlaps the buccal mucosa graft and both are sutured to the urethral mucosa. To the ventral extension, the buccal mucosa is sutured at the urethral mucosa before, and subsequently applies the aPRPg and it is covered by the spongy urethra.

\section{Postoperative care}

The patient consumes a clear liquid diet and ice cream before advancing to a soft, then regular diet. The patient is discharged from the hospital 3 day after surgery. All patients receive postoperative broad-spectrum antibiotics and are maintained on oral antibiotics until the catheter is removed. Three weeks after surgery the Foley catheter is removed.

\section{Postoperative complications}

A possible early minor complication is urethrorrhagia due to nocturnal erections. Possible later minor complications are temporary numbness, dysesthesia to the perineum, and scrotal swelling.

\section{RESULTS}

Clinical outcome was considered a success or a failure at the time that any postoperative procedure was needed, including dilation. No intraoperative or postoperative complications were observed. Transurethral catheter was usually removed after 3 weeks and urethrography was performed after 6 weeks. The uroflowmetry was performed every 3 month and urethrography every 6 month and annually thereafter. Average follow-up was 20 months (range, 12-34 months). No re-strictures at the anastomotic sites were demonstrated in any of the patients. No episode of urinary retention was reported.

\section{Discussion}

The careful examination of the many different actors assembled in a platelet concentrate allows to expect that these products will offer better healing properties than the fibrin glues still used in many surgical applications. And indeed, like fibrin glues many years ago, these technologies were recently tested in many clinical applications, such as oral and maxillofacial surgery (39), EarNose-Throat surgery (41), plastic surgery (42), orthopedics and trauma surgery (46), sports medicine (49), general surgery (51), gynecologic (52) and cardiovascular surgery (53) and even ophtalmology (54). Historically, these technologies were first widely distributed in oral and maxillofacial surgery, and the dental literature is very wide on this topic.

In bone surgery, the classical approach is to mix a bone graft with the platelet gel, and this is one of the first tested applications in maxillofacial surgery. The fibrin matrix is expected to serve as a biological binder between the various bone blocks and to improve the development of the vascularization within the graft, while the growth factors are supposed to accelerate cell proliferation and migration (particularly endothelial cells for angiogenesis). Used as a surgical adjuvant, the platelet concentrates are in fact taking the function of an improved blood clot: indeed in bone surgery, bleeding of the surgical site is always expected, because blood regenerative properties are strongly required for the good integration of a bone graft without necrosis sequestrum (this is an old but validated clinical principle). The use of platelet concentrate is somehow a way to mimic and amplify a natural phenomenon: blood coagulation for tissue regeneration. In soft tissue surgery, the classical approach is to cover the surgical site with a wide layer of fibrin gel (55). The platelet gel serves as a biological binder at the interface 
between the skin and the deep tissues (like a fibrin glue), and is also supposed to accelerate soft tissue healing, through angiogenesis stimulation and proliferation of the skin connective tissues. The main function of the platelet concentrate is therefore to protect the surgical site by stimulating the wound closure and avoiding local necrosis of the skin.

As surgical adjuvants, all the platelet concentrates follow similar concepts of clinical use: mixed with a bone graft or used as protective glue layer for soft tissues. The general philosophy of these preparations is to stimulate healing and reduce the risk of failure (particularly the necrosis of a bone graft or a cutaneous flap), but these products are sometimes also expected to improve the intrinsic quality of the treated tissues: stronger bone graft remodelling and gingival tissue maturation, invisible cutaneous scar, etc.

These surgical adjuvants may be useful in all the sites where biological binder and a stimulation of angiogenesis are required. It is interesting to see that for this kind of applications, fibrin and growth factors are both as important.

Finally, the antimicrobial properties of these preparations are also very important characteristics that offer many collateral applications, such as local disinfection or contamination control of wounds (60). These products could also act as regulators of the immune reactions, directly with their leukocyte content and growth factors (61), but also indirectly through the angiogenic properties of the fibrin matrix (early vascularization helps to drain edema and inflammation).

The concept of in situ regenerative medicine is to inject cells or pharmaceutical preparations with the objective to induce locally the regeneration of a tissue. It is a pharmaceutical concept, where platelet concentrates are no more a surgical adjuvant to the treatment: they become the treatment. This kind of application is an important trend in the field of platelet concentrates, because these preparations contain high concentrations of autologous cells and proteins (particularly growth factors) that could promote a local cell stimulation.

The first application based on this concept is to inject unactivated liquid platelet suspensions in various tissues in order to stimulate locally the cells and tissue regeneration. This non-surgical approach is particularly relevant with tendons or aged skin (49).

The second application is to use these products as solid biomaterials sustaining the release of regenerative molecules on a wounded site. PRP gels technologies allow to produce a significant volume of this fibrin-based biomaterial rich in many healing factors, particularly platelet growth factors.

The literature of Current Pharmaceutical Biotechnology, several experts try to highlight the beneficial impact of these therapies in different clinical fields.

In the gynecology literature, Shackelford et al., conducted a double-blind, randomized, placebo-controlled trial using topical recombinant human Platelet Derived Growth Factors gel (PDGF gel) after abdominal wound separation (64). They used the recombinant growth factor to treat the wound and studied the effects on wound healing. The patients in the placebo group closed $54+/-$
26 days post-operatively, whereas the wounds of patients in the treatment group closed in $35+/-15$ days $(\mathrm{p}=0.05)$. The preliminary study suggests that the topical application of $0.01 \%$ recombinant human PDGF gel accelerates healing of separated surgical wound significantly, as determined by Kaplan-Meier analysis.

PG including multiple growth factors, have been used to treat chronic wounds since 1985 (65). Since this period, a variety of studies have been published on the application of PRP gels in wound care management.

A prospective, randomized, controlled, blinded, multicenter clinical study was conducted by Driver and associates to evaluate the efficacy and safety of autologous PRP gel for the treatment of non-healing diabetic foot ulcers (67). The primary study objective was the proportion of patients with a healed wound. The proportion of completely healed wounds was significantly higher in the PRP gel group when compared to the control group (81.3\% and $42.1 \%$ in the PRP gel and control treatment groups, respectively). Furthermore, no treatment related adverse effects were noted, indicating safe PRP gel preparation and application.

From the literature it is clear that aPRP and PG have a wide and safe application within a variety of operative procedures as a tissue regenerative agent. Its application has extended to patients that are prone to higher surgical complications.

However in our experience the follow-up is limited and no definitive conclusion or comparison can be made with the original BM UP. The use of aPRP gel seems feasible and safe.

The short-term results on this our limited series of patients were satisfactory. Further comparative studies are necessary to confirm that the use aPRP gel is really beneficial. Moreover, additional studies are necessary to evaluate whether its use reduces the re-stricture rate.

\section{Conclusion}

Longer follow-up on a larger series of patients is necessary to confirm our satisfactory preliminary reports using aPRP gel. In our opinion it is important to continue investigating this procedure for its advantages in case of complex urethral stenosis complicated by fibrous spongy, above all in penile urethral stenosis post hypospadia repair. We propose the name of this technique Maselli-Scarcia's.

\section{REFERENCES}

1. Barbagli G, Palminteri E, Lazzeri M, Guazzoni G. Anterior urethral strictures. BJU Int. 2003; 92:497-505.

2. Andrich DE, Leach CJ, Mundy AR. The Barbagli procedure gives the best results for patch urethroplasty of the bulbar urethra. BJU Int. 2001; 88:385-9.

3. Kane CJ, Tarman GJ, Summerton DJ, et al. Multi-institutional experience with buccal mucosa onlay urethroplasty for bulbar urethral reconstruction. J Urol. 2002; 167:1314-7.

4. Elliot SP, Metro MJ, McAninch JW. Long-term followup of the ventrally placed buccal mucosa onlay graft in bulbar urethral reconstruction. J Urol. 2003; 169:1754-7. 
5. Andrich DE, Dunglison N, Greenwell TJ, Mundy AR. The longterm results of urethroplasty. J Urol- 2003; 170:90-2.

6. Barbagli $G$, et al. Anastomotic fibrous rings as cause of stricture recurrence after bulbar onlay graft urethroplasty: an open issue. J Urol. 2006; 175:104, abstract 314.

7. Everts PAM, Overdevest EP, Jakimowicz J, et al. The use of autologous platelet-leukocyte gels to enhance the healing process in surgery, a review. Surg Endosc. 2007; 21:2063-2068.

8. Antoniades HN, Williams LT. Human platelet-derived growth factor: structure and functions. Fed Proc. 1983; 81:2396-2400.

9. Pierce G, Mustoe T, Altrock B. Role of Platelet-Derived Growth Factor in Wound Healing. J Cell Biochem. 1991; 45:319-326.

10. Cieslik-Bielecka A, Gazdzik TS, Bielecki TM, Cieslik T. Why the platelet-rich gel has antimicrobial activity? Oral Surg. Oral Med. Oral Pathol. Oral Radiol. Endod., 2007; 103:303-305.

11. Junqueira LC, Carneiro, J. Basic Histology. McGraw-Hill: New York, 2003, pp. 97-101.

12. Tang YQ, Yeaman MR. Selsted ME. Antimicrobial peptides from human platelets. Infect. Immun. 2002; 70:6524-6533.

13. McGrath MH. Peptide growth factors and wound healing. Clin Plast Surg. 1990; 17:421-432.

14. Cromack DT, Pierce GF, Mustoe TA. TGF and PDGF medicated tissue repair: Identifing mechanisms of action using impaired and normal models of wound healing. Clinical and Experimental Approaches to Dermal and Epidermal Repair: Normal and Chronic Wounds. Wiley Liss: New York, 1991,; pp. 359-373.

15. Brown RL, Breeden MP, Greenhalg DG. PDGF and TGF-alpha act synergistically to improve wound healing in the genetically diabetic mouse. J Surg Res. 1994; 56:562-570.

16. Whitman DH, Berry RL, Green DM. Platelet gel: an autologous alternative to fibrin glue with applications in oral and maxillofacial surgery. J. Oral Maxillofac Surg. 1997; 55:1294-1299.

17. Braccini F, Tardivet L, Dohan Ehrenfest DM. The relevance of Choukroun's Platelet-Rich Fibrin (PRF). during middle ear surgery: preliminary results. Rev. Laryngol Otol Rhinol. (Bord.), 2009; 130:175-180.

18. Man D, Plosker H, Winland-Brown JE. The use of autologous platelet-rich plasma (platelet gel) and autologous platelet-poor plasma (fibrin glue) in cosmetic surgery. Plast Reconstr Surg. 2001; 107:229-237; discussion 238-229.

19. Everts PA, Devilee RJ, Brown Mahoney C, et al. Platelet gel and fibrin sealant reduce allogeneic blood transfusions in total knee arthroplasty. Acta Anaesthesiol Scand. 2006; 50:593-599.

20. Mishra A, Woodall J. Jr., Vieira A. Treatment of tendon and muscle using platelet rich plasma. Clin Sports Med. 2009; 28:113-125.

21. Everts PA, Overdevest EP, Jakimowicz JJ, et al. The use of autologous platelet-leukocyte gels to enhance the healing process in surgery, are view. Surg Endosc. 2007; 21:2063-2068.

22. Fanning J, Murrain L, Flora R, et al. Phase I/II prospective trial of autologous platelet tis- sue graft in gynecologic surgery. J Minim Invasive Gynecol. 2007; 14:633-637.

23. Khalafi RS, Bradford DW, Wilson MG. Topical application of autologous blood products during surgical closure following a coronary artery bypass graft. Eur J Cardiothorac Surg. 2008; 34:360-364.

24. Alio JL, Abad M, Artola A, et al. Use of autologous platelet-rich plasma in the treatment of dormant corneal ulcers. Ophthalmology. 2007; 114:1286-1293.
25. Man D, Plosker H, Winland-Brown JE. The use of autologous platelet-rich plasma (platelet gel) and autologous platelet-poor plasma (fibrin glue) in cosmetic surgery. Plast Reconstr Surg. 2001; 107:229-237.

26. Cieslik-Bielecka A, Bielecki T, Gazdzik, et al. Autologous platelets and leukocytes can im-prove healing of infected high-energy soft tissue injury. Transfus Apher Sci. 2009; 41:9-12.

27. Woodall J Jr., Tucci M, Mishra A, Benghuzzi H. Cellular effects of platelet rich plasma: a study on HL-60 macrophage-like cells. Biomed Sci Instrum. 2007; 43:266-271.

28. Shackelford DP, Fackler E, Hoffman MK, Atkinson S. Use of topical recombinant human platelet-derived growth factor $B B$ in abdominal wound separation. Am. J. Obstet. Gynecol. 2002; 186:701-704.

29. Knighton DR, Ciresi K, Fiegel VD, et al. Simulation of repair in chronic, nonhealing, cutaneous ulcers using platelet-derived wound healing formula. Surg Gyn Obstet. 1990; 170:56-58.

30. Driver VR, Hanft J, Fylling CP, Beriou JM. A prospective, randomized, controlled trial of autologous platelet-rich plasma gel for the treatment of diabetic foot ulcers. Ostomy Wound Manag. 2006; 52:68-87.

\section{Correspondence}

Marcello Scarcia, MD (Corrisponding Author) scarciam@hotmail.com

Francesco Paolo Maselli, MD ciccio702001@gmail.com

Giuseppe Cardo MD, MD giuseppecardo@hotmail.com

Giuseppe Mario Ludovico, MD giuseppeludovico@hotmail.com Urology Department of General Hospital "F. Miulli" S.P. Santeramo km 4.100 - 70021 Acquaviva delle Fonti, Bari, Italy 